\title{
Effects of noninvasive ventilation on dynamic hiperinflation of patients with COPD during activities of daily living with upper limbs
}

\section{Efeitos da ventilação não-invasiva sobre a hiperinsuflação dinâmica de pacientes com DPOC durante atividade da vida diária com os membros superiores}

Isabela M. B. Sclauser Pessoa ${ }^{1,2}$, Dirceu Costa 3 , Marcelo Velloso ${ }^{4}$, Eliane Mancuzo ${ }^{5}$, Marco A. S. Reis ${ }^{6}$, Verônica F. Parreira ${ }^{4}$

\begin{abstract}
Background: Patients with chronic obstructive pulmonary disease (COPD) complain of dyspnea on activities of daily living (ADLs) with the upper limbs. Dynamic hyperinflation $(\mathrm{DH})$ is one of the ventilatory mechanisms that may contribute towards dyspnea. To minimize the $\mathrm{DH}$ it is indicated the use of noninvasive ventilation (NIV). Objectives: To verify whether there is $\mathrm{DH}$ and dyspnea during the performance of ADL with the upper limbs with and without the use of NIV. Methods: 32 patients with moderate-to-severe COPD, aged 54 to 87 years (mean 69.4, SD 7.4) were evaluated. The subjects lift up containers weighing between 0.5 and $5.0 \mathrm{~kg}$ over a fiveminute period, starting from the waist level and putting them onto a shelf located above head height, with and without the use of NIV (BiPAP ${ }^{\oplus}$; IPAP $10 \mathrm{cmH}_{2} \mathrm{O}$; EPAP $4 \mathrm{cmH}_{2} \mathrm{O}$ ). The inspiratory capacity (IC) and dyspnea (Borg scale) were evaluated on all the patients. The IC was measured before and after simulation of the ADL. In order to analyze the data, Student's test for dependent samples and the Wilcoxon test were used. Results: There were statistically significant reductions in IC after the ADL with and without NIV ( $p=0.01$ ). The dyspnea increased after the ADL with and without the NIV, however between both interventional procedures protocols no betweengroup difference was observed. Conclusions: The simulation of an ADL with the upper limbs resulted in an increase in $\mathrm{DH}$ and dyspnea. The NIV supplied with pre-established pressure was not enough to prevent the $\mathrm{DH}$ and dyspnea.
\end{abstract}

Keywords: physical therapy; dynamic hyperinflation; noninvasive ventilation; chronic obstructive pulmonary disease; activities of daily living

\section{Resumo}

Contextualização: Pacientes com doença pulmonar obstrutiva crônica (DPOC) queixam-se de dispneia nas atividades de vida diária (AVD) com os membros superiores (MMSS). A hiperinsuflação dinâmica (HD) é um dos mecanismos ventilatórios que contribuem para a dispneia. Para minimizar a HD, propõe-se a utilização de sistemas de ventilação não-invasiva (VNI). Objetivos: Verificar se existe HD e dispneia durante a realização de uma AVD com os MMSS com e sem o uso da VNI. Métodos: Participaram 32 pacientes com DPOC de moderada a muito grave, com idades entre 54 a 87 anos $(69,4 \pm 7,4)$. Os pacientes elevaram potes com pesos de 0,5 a $5 \mathrm{~kg}$ durante 5 minutos, iniciando a elevação a partir da cintura pélvica em direção a uma prateleira localizada acima da cabeça, com e sem o uso da VNI (BiPAP ${ }^{\circledR}$; IPAP $10 \mathrm{cmH}_{2} \mathrm{O}$; EPAP $4 \mathrm{cmH}_{2} \mathrm{O}$ ). Foram avaliadas a capacidade inspiratória (Cl) e a dispneia (Escala de Borg). A Cl foi mensurada antes e após a simulação da AVD. Na análise dos dados foram utilizados o teste $t$ de Student para amostras dependentes e o teste de Wilcoxon. Resultados: Houve redução significativa da Cl após a AVD com e sem VNI ( $p=0,01)$. A dispneia aumentou após a AVD com e sem a VNI, mas entre ambos os protocolos não houve diferença. Conclusões: A simulação da AVD com os MMSS resultou em aumento da HD e dispneia. A VNI ofertada com pressões preestabelecidas não foi suficiente para evitar a HD e a dispneia.

Palavras-chave: fisioterapia; hiperinsuflação dinâmica; ventilação não-invasiva; doença pulmonar obstrutiva crônica; AVD

Received: 07/14/2011 - Revised: 09/07/2011 - Accepted: 10/04/2011

\footnotetext{
'Physical Therapy Department, Universidade Católica de Minas Gerais (PUC/Minas), Belo Horizonte, MG, Brazil

${ }^{2}$ Program of Post Graduation in Rehabilitation Sciences, Universidade Federal de Minas Gerais (UFMG), Belo Horizonte, MG, Brazil

${ }^{3}$ Program of Post Graduation in Rehabilitation Sciences, Universidade Nove de Julho (UNINOVE), São Paulo, SP, Brazil

${ }^{4}$ Department of Physical Therapy, UFMG, Belo Horizonte, MG, Brazil

${ }^{5}$ Department of Medical Clinic, Faculdade de Medicina, UFMG, Belo Horizonte, MG, Brazil

${ }^{6}$ Faculdade de Ciências Médicas de Minas Gerais (FCMMG), Belo Horizonte, MG, Brazil

Correspondence to: Verônica Franco Parreira, Departamento de Fisioterapia - EEFFTO, Universidade Federal de Minas Gerais, Av. Presidente Antônio Carlos, 6627, Pampulha, Belo Horizonte,

MG, Brasil, e-mail: veronicaparreira@yahoo.com.br
} 


\section{Introduction $: \because$.}

Chronic obstructive pulmonary disease (COPD) is characterized by a progressive airflow obstruction and dyspnea and is the main complaint reported by patients ${ }^{1}$. Dyspnea is a common complaint in patients with chronic lung disease during physical activities, which lead to a chronic physical inactivity and sedentary lifestyle. Paradoxically, this lifestyle induces increased ventilatory demand for the same activity, feeding the dyspnea-inactivity-dyspnea cycle ${ }^{1}$.

The upper limbs (ULs) are used extensively in daily life for carrying out activities of daily living (ADLs). As the disease progresses, patients have thoracoabdominal asynchrony, increase the oxygen consumption and increase the minute ventilation (VE) during efforts using of the ULs without support ${ }^{2,3}$. According to Tangri and Woolf ${ }^{4}$, patients with COPD present an irregular, superficial and rapid breathing pattern followed by dyspnea during activities such as tying their shoes.

According to McKeough, Alison and Bye ${ }^{5}$ there are changes in static lung volumes of patients with moderate-to-severe COPD when the ULs are raised without support above $90^{\circ}$ of flexion. There is an increase in functional residual capacity (FRC) and a reduction in inspiratory capacity (IC), which characterizes the dynamic pulmonary hyperinflation $(\mathrm{DH})^{6}$.

In the DH occurs an increase in ventilatory demand contributing to the severe dyspnea reported by the patients ${ }^{7}$. According to Porto et al. ${ }^{8}$ exercises performed with the ULs lead to a greater DH compared with exercise performed with the lower limbs (LL). A therapeutic approach aimed to reduce DH during exercises and to interrupt the dyspnea-inactivity-dyspnea cycle is the use of noninvasive ventilation (NIV) ${ }^{9,10}$. The NIV has been used more recently associated with the training of LL in order to increase the exercise tolerance ${ }^{10,11}$. This therapy provides a reduction of dyspnea by decreasing the burden on the respiratory muscles as a result of $\mathrm{DH}$; resulting therefore, in a greater amount of blood flow to peripheral muscles, which allows the patient to achieve higher intensities during the exercise ${ }^{12}$.

Therefore, the objective of this study was to determine whether there are dynamic pulmonary hyperinflation and dyspnea during the performance of an activity with the upper limbs, simulating activities of daily living, with and without the use of noninvasive ventilation in COPD patients.

\section{Methods}

\section{Sample}

This study was conducted in a Pulmonary Function Laboratory, where 32 patients with COPD were evaluated.
The participants were recruited from a school clinic of an academic institution and from the local community. The sample size calculation was based on the inspiratory capacity variable analyzed in the study of Marin et al. ${ }^{7}$, which had an effect of moderate magnitude $(d=0.71)$, a statistical power of 0.80 and significance level $\alpha=0.05$. Considering an inferential analysis with non-directional test, significance level $\alpha=0.05$ and the sample size needed to detect the desired effect was 22 patients.

The following inclusion criteria were established: patients with COPD stages II to IV according to the criteria of the Global Initiative for Chronic Obstructive Pulmonary Disease $^{1}$, presenting lung hyperinflation with values of total lung capacity (TLC) $>120 \%$ of predicted ${ }^{13}$ and/or the ratio between the forced expiratory volume in one second and the forced vital capacity $\left(\mathrm{FEV}_{1} / \mathrm{FVC}\right)<70 \%$ and $\mathrm{FEV}_{1}<80 \%$; air trapping represented by the increase in residual volume (RV) and the ratio RV/TLC $>140 \%$ and $>40 \%$ of predicted $^{13}$; in stable clinical conditions, without pulmonary infection four weeks prior the tests and reporting dyspnea during ADL the with the ULs.

Patients presenting asthma, heart failure, orthopedic impairments of the shoulder girdle, recent surgery, history of thoracic fractures, pneumothorax, and claustrophobia were excluded from the study.

This study was approved by the Ethics Committee of the Universidade Metodista de Piracicaba (UNIMEP), Piracicaba, SP, Brazil, number 75/05. All participants signed a consent form.

\section{Instruments and measures}

\section{Static and dynamic spirometry analysis}

To perform spirometry and to measure the static lung volumes, a whole-body plethysmograph (Vmax22 Autobox, Sensormedics Corporation, Yorba Linda, CA $)^{14}$ was used. The evaluations of the TLC, IC, FRC and RV were performed with the patient sitting in the plethysmograph chamber with constant volume and variable pressure. The pulmonary function tests were performed according to the recommendations of the American Thoracic Society ${ }^{15}$. In order to evaluate the pulmonary function under optimized ventilatory conditions, the patients performed the pulmonary function tests 20 minutes after the inhalation of $400 \mathrm{mg}$ of salbutamol via nebulizer ${ }^{7}$, in the same day of the procedures described below.

\section{Inspiratory capacity (IC) analysis}

To measure the IC, patients breathed through a mouthpiece wearing a nose-clip. Each respiratory cycle was measured using an automated metabolic and ventilatory measurement system (Vmax229d Cardiopulmonary Exercise Testing Instrument 
SensorMedics, Yorba Linda, CA). The equipment was calibrated prior to the beginning of the data collection. The evaluation of this variable is based on the analysis of the inspiratory and expiratory flow-volume loops. The $\mathrm{DH}$ is demonstrated by the shift of the inspiratory and expiratory loops to the left, as a result of the reduction in IC and the increase of FRC. As the TLC does not change during exercise in patients with COPD, the change in the capacities mentioned above demonstrated the occurrence of the $\mathrm{DH}^{16,17}$.

Firstly, the patient performed the spirometric FVC maneuvers. This maneuver was chosen based on its acceptability and reprodutibility ${ }^{14}$. After four to six respiratory cycles, in the FRC level, patients were instructed to breathe in until the TLC, with the command "take a deep breath" and at the end they returned to basal breathing in order to establish the basal IC. The greater maneuver from two reproducible IC maneuvers was selected for analysis before the beginning of the ADL simulation ${ }^{7}$. After the intervention, the patients were asked immediately to perform two IC maneuvers following the same verbal command. Due to the proximity of the end of the procedures the first maneuver was chosen for analysis.

\section{Analysis of respiratory distress}

In order to describe the sample, the modified Medical Research Council scale ${ }^{18}$ (MRC) was used, which includes five situations of physical activity that lead to dyspnea. This scale ranges from 0 to 4 , where $0=$ no dyspnea, except during strenuous exercise and 4 = dyspnea prevents you from leaving the house or dyspnea occurs while you dress or undress your clothes. To evaluate the effect of the intervention on dyspnea, the modified Borg scale ${ }^{19}$ was used, where 0 represents the absence of respiratory fatigue and 10 the greatest feeling of respiratory fatigue, on a scale raging from 0 to 10 .

\section{Intervention}

The patients underwent into two different interventional procedures, named Protocol 1 and 2: Protocol 1: ADL - simulation of an ADL that involves elevation of the upper limbs; Protocol 2: ADL + NIV - simulation of an ADL that involves elevation of the upper limbs associated to NIV, performed with positive airway pressure ventilator $\left(\right.$ BiPAP $^{\circledR}$, Respironics ${ }^{\circledR}$ - Auto Trak Sensitivity, Murrysville, Pennsylvania, USA). The interventional procedures order was randomized by drawing lots.

\section{Protocol $1-A D L$}

The following ADL were simulated by the participants: lift containers with weights of $0.5,1,2,3,4$ and $5 \mathrm{~kg}$, during a period of five minutes, with both arms extended, picking up the containers from a waist high surface and positioning them on a shelf located above the head ${ }^{3}$. The activity started by lifting the lightest container and continued progressively with the heaviest ones, until the completion the entire series. The series were repeated as often as necessary, within the total time of 5 minutes, and the number of completed series was not taken into consideration.

\section{Protocol $2-A D L \pm N I V$}

The interventional procedure was the same that the one performed in the protocol 1 , however the performance of the activity was associated with the NIV, using the $\operatorname{BiPAP}^{\circledR}$. The inspiratory pressure (IPAP) was set at $10 \mathrm{cmH}_{2} \mathrm{O}$ and the expiratory pressure (EPAP), at $4 \mathrm{cmH}_{2} \mathrm{O}$. All patients used a face mask (Respironics Cpap Mask Comfortfull 2w Premium, Sao Paulo). Prior to the performance of the activity associated with NIV, the patients underwent to a brief period of adaptation and orientation, which consisted in increasing the pressure gradually until the preset pressure level that was established during the dyspnea analysis and the changes in vital signs: respiratory rate (RR), heart rate (HR - Polar $\left.{ }^{\circledR}\right)$ and peripheral saturation of hemoglobin $\left(\mathrm{SpO}_{2}-\mathrm{Nonim}^{\circledR}\right.$, USA).

Whenever it was observed a decrease in $\mathrm{SpO}_{2}$ below $90 \%$ during the performance of both interventional procedures protocols, the activities were stopped and oxygen was given by nasal cannula (protocol 1) and by face mask (protocol 2) in order to maintain $\mathrm{SpO}_{2}$ above $90 \%$.

\section{Study design and procedures}

Figure 1 presents the study design and the procedures performed during this study. At the end of the first interventional protocol, the patient rested long enough for the $\mathrm{SpO}_{2}$, HR and $\mathrm{RR}$ returned to baseline values and then they performed of the second interventional protocol. These variables were measured 15 minutes after the performance of the first protocol. If the return to baseline value was not reached, a new evaluation was performed every 15 minutes, establishing a maximum period of 60 minutes to return to baseline values.

\section{Statistical analysis}

Data are shown as mean \pm standard deviation. The distribution of variables was tested using the Shapiro-Wilk tests. All variables were normally distributed with the exception of the fatigue sensation variable. Statistical analysis was performed using the Student $t$ test for paired samples. The analysis of the fatigue sensation variable, the Wilcoxon test was used. The significance level of $5 \%$ was established. The analyses were performed by using the statistical package $\mathrm{SAS}^{\circledR}$ - Statistical Analysis System, 12.0, Carey, NC, USA. 


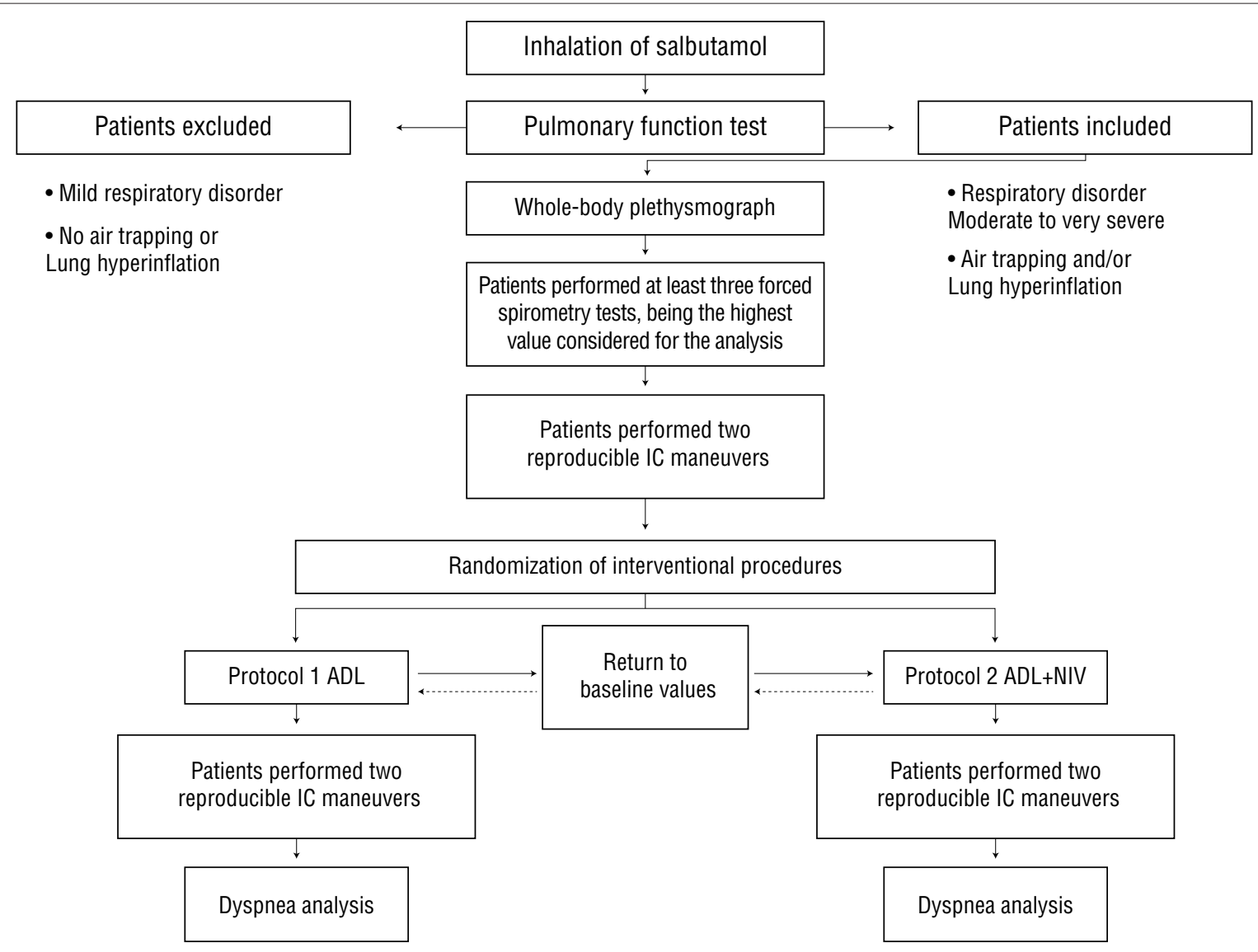

Figure 1. Study design and procedures.

\section{Results $: \because$.}

Initially, 33 patients were evaluated, of whom 1 participant had an obstruction stage II, however without pulmonary hyperinflation and air-trapping, being excluded from the study. Therefore, 32 patients underwent both interventional protocols on the same day, as the variables IC, $\mathrm{SpO}_{2}$ and $\mathrm{HR}$ returned to baseline values within 45 minutes.

Table 1 shows the characteristics of patients according to gender, age, body mass index (BMI), years/pack of cigarettes and pulmonary function test. The patients presented $\mathrm{FEV}_{1}$ between $22 \%$ and $64 \%$ of predicted. All participants presented air-trapping ( $\mathrm{n}=32$ ) being only 12 of them with pulmonary hyperinflation. Thirteen patients had a score of 4 on MRC scale; 15 had a score of 3 and four patients had a score of 2 . All patients reported dyspnea while performing weight-bearing ADLs with the ULs elevated.

Table 2 shows the results for the IC before and after the completion of the two interventional protocols. There was a statistically significant decrease in IC after the completion of both interventional protocols.

Figure 2 shows the data related to the IC after the completion of the two interventional protocols. There was no statistically significant difference between the IC maneuvers after the completion of ADL with and without the association of NIV.
Table 1. Characteristics of patients with COPD.

\begin{tabular}{|c|c|}
\hline Characteristics & Patients with COPD $($ mean $\pm S D)(n=32)$ \\
\hline Gender: M/F & $24 / 8$ \\
\hline Age (yr) & $69.38 \pm 7.36$ \\
\hline Body Mass (kg) & $65.04 \pm 13.76$ \\
\hline Height (cm) & $147.53 \pm 50.08$ \\
\hline Pack-years (smoke) & $78.03 \pm 42.51$ \\
\hline $\mathrm{FEV}_{1}-\mathrm{L}$ (\% predicted) & $1.03 \pm 0.36(42 \pm 13)$ \\
\hline FVC-L (\% predicted) & $2.73 \pm 0.84(89 \pm 23)$ \\
\hline $\mathrm{FEV}_{1} / \mathrm{FVC} \%$ & $42 \pm 12$ \\
\hline TLC-L (\% predicted) & $7.03 \pm 1.46(120 \pm 31)$ \\
\hline FRC-L (\% predicted) & $5.19 \pm 1.37(160 \pm 52)$ \\
\hline VR-L (\% predicted) & $4.27 \pm 1.35(228 \pm 124)$ \\
\hline $\mathrm{RV} / \mathrm{TLC} \%$ & $61 \pm 10$ \\
\hline IC \% predicted & $67 \pm 15$ \\
\hline IC/TLC \% & $26 \pm 7$ \\
\hline
\end{tabular}

Data are presented as mean \pm Standard Deviation. $C O P D=$ chronic obstructive pulmonary dise-

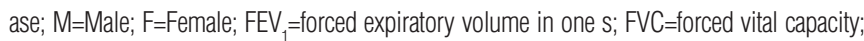

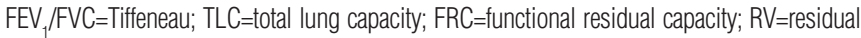
volume; IC=inspiratory capacity and IC/TLC=inspiratory fraction.

Figure 3 shows the data related to the evaluation of dyspnea after the completion of both interventional protocols. It was observed that the performance of the interventional procedures promoted a significant increase in dyspnea after the completion of both protocols, with no difference between them. 
Table 2. Inspiratory capacity in patients with COPD ( $n=32)$ before and after ADL with or without NIV.

\begin{tabular}{lccc}
\hline $\begin{array}{l}\text { linterventional } \\
\text { Procedures Protocol }\end{array}$ & Before & After & p Value \\
\hline ADL & $2.06 \pm 0.60 \mathrm{~L}$ & $1.69 \pm 0.60 \mathrm{~L}$ & $0.0001^{*}$ \\
\hline $\mathrm{ADL}+\mathrm{NIV}$ & $2.05 \pm 0.62 \mathrm{~L}$ & $1.73 \pm 0.57 \mathrm{~L}$ & $0.0001^{*}$ \\
\hline
\end{tabular}

Data are presented as mean \pm Standard Deviation; $I C=$ =inspiratory capacity; COPD=chronic

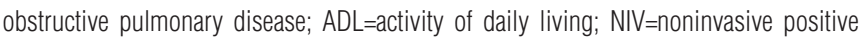
pressure ventilation and ${ }^{*} p<0.05$.

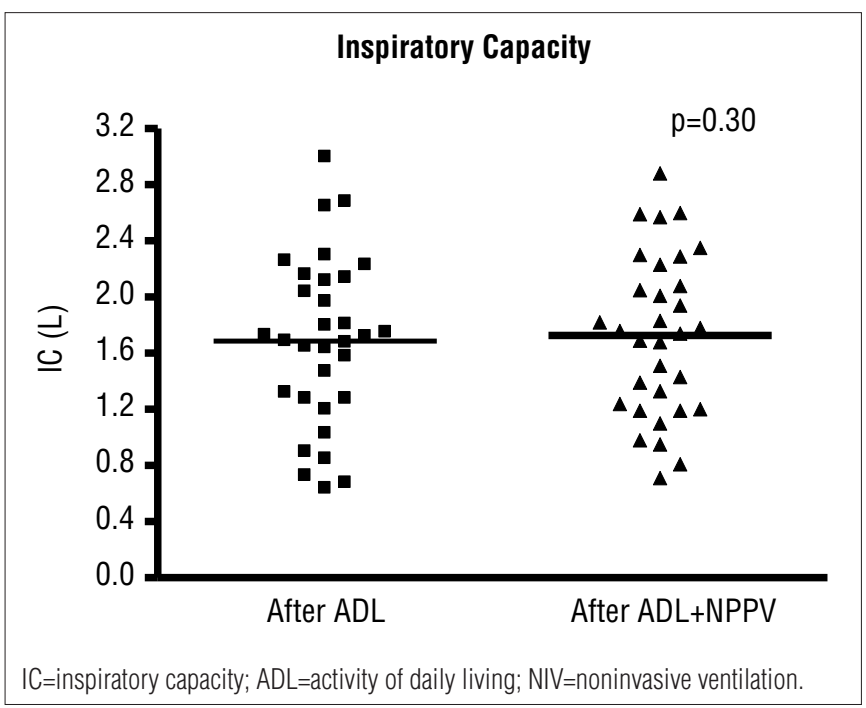

Figure 2. Data are presented as absolute values and means.

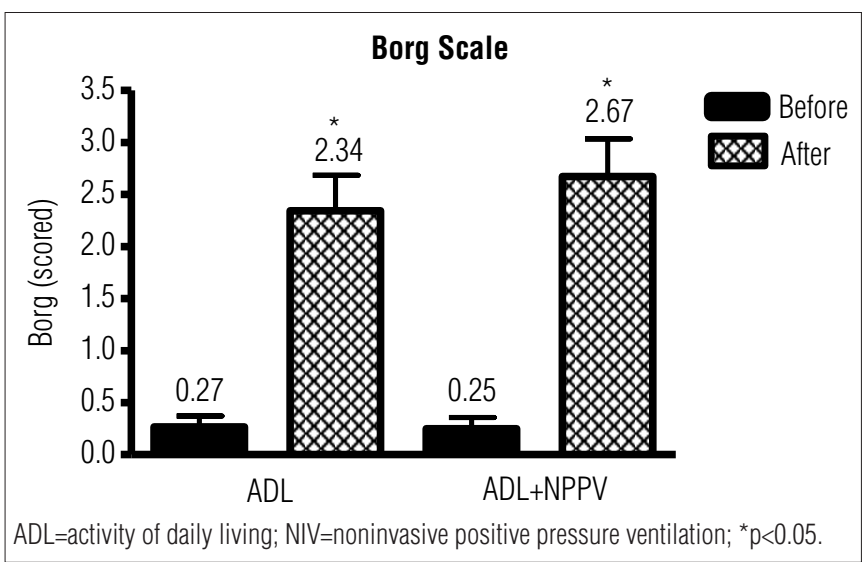

Figure 3. Data are presented as median.

\section{Discussion $: \because$.}

The main results observed in this study were: 1) there was a statistically significant decrease in IC with the simulation of an $\mathrm{ADL}$, associated or not with noninvasive ventilation, demonstrating DH; 2) a statistically significant difference was not observed in the comparison of the IC after the completion of both protocols and 3) there was a significant increase in dyspnea after the completion of both protocols, with no difference between them.
The DH observed in patients with COPD leads to dyspnea and limits the capacity to perform physical exercises ${ }^{2}$. The hypothesis of this study was that NIV performed with two levels of positive pressure (IPAP of $10 \mathrm{cmH}_{2} \mathrm{O}$ and EPAP of $4 \mathrm{cmH}_{2} \mathrm{O}$ ) would decrease dyspnea and pulmonary intrinsic pressure (PEEPi), and consequently would decrease the $\mathrm{DH}$.

The ventilatory pattern during activities with the elevation of the ULs influences the onset of DH in patients with COPD who have difficulty to optimize the VE by the increase in the Tidal Volume $(\mathrm{Vt})^{5,20-22}$. In a recently study, Colucci et al. ${ }^{23}$ verified the association between different intensities of exercises with the ULs (50, 65 and $80 \%$ of maximum load during a ergometer cycle exercises) and the $\mathrm{DH}$ in patients with severe COPD. These authors observed that higher loads of exercise were associated with DH and a lower tolerance to exercise and $80 \%$ of the maximum load represented lower work efficiency (measured by the ratio $\mathrm{VO}_{2}(\mathrm{ml} / \mathrm{kg}) /$ exercise duration).

The ventilatory strategy of these patients to increase the $\mathrm{VE}$ is to increase the RR, since the TLC does not change with exercise $^{16,17}$. The premature end of exhalation increases even more the air-trapping, decreasing therefore the $\mathrm{IC}^{6}$. In the present study, the use of NIV with pre-determined and not individualized values (IPAP $10 \mathrm{cmH}_{2} \mathrm{O}$ and EPAP $4 \mathrm{cmH}_{2} \mathrm{O}$ ) aimed to standardizing the intervention, and the choice of the used pressures was based on several studies, ${ }^{9,24,26-28}$ which have demonstrated the benefits of using these pressures during exercises with the LLs. To our knowledge there are no studies that have associated the simulation of an ADL with NIV.

Nava et al..$^{24}$ found a reduction in the activity of the diaphragm muscle measured by the decrease in transdiaphragmatic pressure as well as a significant decrease in RR and a parallel increase in the Vt when an IPAP of $10 \mathrm{cmH}_{2} \mathrm{O}$ or $20 \mathrm{cmH}_{2} \mathrm{O}$, associated with an EPAP of $5 \mathrm{~cm} \mathrm{H}_{2} \mathrm{O}$, was applied in stable and hypercapnic patients with severe COPD during basal respiration.

The artificial ventilation support may improve exercise tolerance and may help patients with severe COPD to achieve higher level of training ${ }^{25-27}$. Van't Hul et al..$^{26}$ evaluated the effects of exercise training with only pressure support ventilation (PSV of 10 or $5 \mathrm{cmH}_{2} \mathrm{O}$ ) in patients with moderate to very severe COPD. These authors found that in the assistance level of $10 \mathrm{cmH}_{2} \mathrm{O}$, there was a reduction in the VE by the reduction in the RR. The authors suggested that the changes in the respiratory pattern may have reduced the $\mathrm{DH}$, which justified the increased tolerance to high-intensity training in these patients.

Maltais, Reissmann and Gottfried ${ }^{9}$ evaluated the respiratory pattern, dyspnea and inspiratory effort in patients with moderate-to-severe COPD, performing a constant load test on the ergometer cycle, associated with the use of SP of $10 \mathrm{cmH}_{2} \mathrm{O}$. These authors found an increase in the VE by the increase in 
RR and Vt, however with a significant decrease in the inspiratory effort and dyspnea.

Poggi et al. ${ }^{27}$ investigated the effects of two types of artificial ventilation (PAV and PSV - both with IPAP, established according to patients comfort, and EPAP of $4 \mathrm{cmH}_{2} \mathrm{O}$ ) during elevation of the ULs in patients with severe COPD. In both modes of ventilation, there was a reduction of the PEEPi greater than $30 \%$ compared with the control group, however this difference was not statistically significant. It should be noted, however, that the group that used the PAV method reported lower inspiratory effort during the elevation of the ULs.

O'Donnell, Sanii and Younes ${ }^{28}$, in an innovative study, evaluated the impact of the use of CPAP of 4 to $5 \mathrm{cmH}_{2} \mathrm{O}$ in patients with moderate-to-severe COPD and observed a reduction of dyspnea during the performance of submaximal exercise on the treadmill, suggesting that positive pressure promoted the reduction of $\mathrm{DH}$.

With regards to the IPAP established in order to provide support to the inspiratory muscles, especially to the diaphragm muscle, it is possible that the selected pressure of $10 \mathrm{cmH}_{2} \mathrm{O}$ was not adequate to achieve this goal when the simulation of a ADLs was performed. There was a significant increase in dyspnea, which indicates indirectly an overload of the inspiratory muscles. According to the findings of the present study, it appears that the EPAP of $4 \mathrm{cmH}_{2} \mathrm{O}$ was insufficient to counterbalance the PEEPi and, therefore, to reduce the overload of the inspiratory muscles in these patients. Studies show that patients with COPD usually complain of a more intense dyspnea when performing prolonged tasks involving the upper limbs in elevated positions and without support compared to tasks with $\mathrm{LLs}^{3,4,8,29}$. This fact demonstrates the possibility of ULs exercises to generate greater impact on DH compared with LLs exercises.

This study has some limitations. Firstly the RR, the transdiaphragmatic pressure and the PEEPi, which could explain the absence of a reduction in the elastic and resistive work of the respiratory muscles, were not measured after the interventional procedures protocols. Therefore, the preestablished pressures may have been inadequate for some patients. Secondly, studies show that other forms of artificial ventilation, such as proportional assisted ventilation, PAV, may provide better results compared to the two fixed pressure levels established in this study, since the PAV suit better to the patient's ventilatory demand ${ }^{30}$.

The main purpose of using NIV during the exercise is to reduce dyspnea by reducing the overload imposed on the respiratory muscles as a result of $\mathrm{DH}$, allowing patients to achieve higher intensity during exercise ${ }^{30}$. The reduction in the overload of respiratory muscles during exercise reduces blood flow competition between these muscles and the peripheral muscles, contributing to an increased of blood supply to the muscles ${ }^{12}$. In the Velloso et al. $^{3}$ study, in patients with COPD performing four ADLs involving the ULs (sweeping the floor, clearing a whiteboard, lifting containers of different weights and changing light bulbs), was observed an increase in the ratio VE on the maximum voluntary ventilation, justifying the intense dyspnea reported by these patients, although the $\mathrm{DH}$ has not been evaluated. Our results showed that the addition of NIV was not able to significantly reduce dyspnea during a simulation of ADL, which may be due to the use of pressures (IPAP and EPAP) beyond the requirements of the patients.

Therefore, our results suggest that the bi-level pressure modality, with IPAP and EPAP of 10 and $4 \mathrm{cmH}_{2} \mathrm{O}$, respectively, was not sufficient to prevent the $\mathrm{DH}$ and dyspnea during $\mathrm{ADL}$ with the ULs in patients with moderate-to-severe COPD. The search for therapeutic strategies to improve the functionality of the patient with COPD during the performance of ADLs is extremely important, considering that $80 \%$ of the functionality is performed by ULs tasks ${ }^{8}$.

We suggest future studies to examine the effects of NIV during ADL with the ULs using other pressures or modalities of NIV, since the functional independence during ADL is a major goal of respiratory physical therapy in the treatment of patients with COPD.

\section{References $: \because$.}

1. Rabe KF, Hurd S, Anzueto A, Barnes PJ, Buist SA, Calverley P, et al. Global strategy for the diagnosis, management, and prevention of chronic obstructive pulmonary disease: GOLD executive summary. Am J Respir Crit Care Med. 2007;176(6):532-55

2. O'Donnell DE. Hyperinflation, dyspnea, and exercise intolerance in chronic obstructive pulmonary disease. Proc Am Thorac Soc. 2006;3(2):180-4

3. Velloso M, Stella SG, Cendon S, Silva AC, Jardim JR. Metabolic and ventilatory parameters of four activities of daily living accomplished with arms in COPD patients. Chest. 2003;123(4):1047-53

4. Tangri S, Woolf $\mathrm{CR}$. The breathing pattern in chronic obstructive lung disease during the performance of some common daily activities. Chest. 1973;63(1):126-7.
5. McKeough ZJ, Alison JA, Bye PT. Arm positioning alters lung volumes in subjects with COPD and healthy subjects. Aust J Physiother. 2003;49(2):133-7.

6. Dolmage TE, Goldstein RS. Repeatability of inspiratory capacity during incremental exercise in patients with severe COPD. Chest. 2002;121(3):708-14.

7. Marin JM, Carrizo SJ, Gascon M, Sanchez A, Gallego B, Celli BR. Inspiratory capacity, dynamic hyperinflation, breathlessness, and exercise performance during the 6-minute walk test in Chronic Obstructive Pulmonary Disease. Am J Respir Crit Care Med. 2001;163(6):1395-9.

8. Porto EF, Castro AA, Velloso M, Nascimento O, Dal Maso F, Jardim JR. Exercises using the upper limbs hyperinflate COPD patients more than exercises using the lower limbs at the same metabolic demand. Monaldi Arch Chest Dis. 2009;71(1):21-6. 
9. Maltais F, Reissmann H, Gottfried SB. Pressure support reduces inspiratory effort and dyspnea during exercise in chronic airflow obstruction. Am J Respir Crit Care Med. 1995;151(4):1027-33

10. Gosselink R. Breathing techniques in patients with chronic obstructive pulmonary disease (COPD). Chron Respir Dis. 2004;1(3):163-72.

11. Mehta S, Hill NS. Noninvasive ventilation. Am J Respir Crit Care Med. 2001;163(2):540-77.

12. Ambrosino N. Assisted ventilation as an aid to exercise training: a mechanical doping? Eur Respir J. 2006;27(1):3-5.

13. Albuquerque AL, Nery LE, Villaça DS, Machado TY, Oliveira CC, Paes AT, et al. Inspiratory fraction and exercise impairment in COPD patients GOLD stages II-III. Eur Respir J. 2006;28(5):939-44

14. Diretrizes para testes de função pulmonar. Jornal de Pneumologia. 2002;28(Suppl 3):95-100.

15. Lung function testing: selection of reference values and interpretative strategies. American Thoracic Society. Am Rev Respir Dis. 1991;144(5):1202-18.

16. Stubbing DG, Pengelly LD, Morse JL, Jones NL. Pulmonary mechanics during exercise in subjects with chronic airflow obstruction. J Appl Physiol. 1980;49(3):511-5.

17. Yan S, Kaminski D, Sliwinski P. Reliability of inspiratory capacity for estimating end-expiratory lung volume changes during exercise in patients with chronic obstructive pulmonary disease. Am J Respir Crit Care Med. 1997;156(1):55-9.

18. Surveillance for respiratory hazards in the occupational setting [American Thoracic Society]. Am Rev Respir Dis. 1982;126(5):952-6.

19. Borg GA. Psychophysical bases of perceived exertion. Med Sci Sports Exerc. 1982;14(5):377-81.

20. Cerny FJ, Ucer C. Arm work interferes with normal ventilation. Appl Ergon. 2004;35(5):411-5.
21. Dolmage TE, Maestro L, Avendano MA, Goldstein RS. The ventilatory response to arm elevation of patients with chronic obstructive pulmonary disease. Chest. 1993;104(4):1097-100.

22. Gigliotti F, Coli C, Bianchi R, Grazzini M, Stendardi L, Castellani C, et al. Arm exercise and hyperinflation in patients with COPD: effect of arm training. Chest. 2005;128(3):1225-32.

23. Colucci M, Cortopassi F, Porto E, Castro A, Colucci E, lamonti VC, et al. Upper limb exercises using varied workloads and their association with dynamic hyperinflation in patients with COPD. Chest. 2010;138(1):39-46.

24. Nava S, Ambrosino N, Rubini F, Fracchia C, Rampulla C, Torri G, et al. Effect of nasal pressure support ventilation and external PEEP on diaphragmatic activity in patients with severe stable COPD. Chest. 1993;103(1):143-50.

25. Díaz 0 , Bégin P, Torrealba B, Jover E, Lisboa C. Effects of noninvasive ventilation of lung hyperinflation in stable hypercapnic COPD. Eur Respir J. 2002;20(6):1490-8.

26. van't Hul A, Gosselink R, Hollander P, Postmus P, Kwakkel G. Training with inspiratory pressure support in patients with severe COPD. Eur Respir J. 2006;27(1):65-72.

27. Poggi R, Appendini L, Polese G, Colombo R, Donner CF, Rossi A. Noninvasive proportional assist ventilation and pressure support ventilation during arm elevation in patients with chronic respiratory failure. A preliminary, physiologic study. Respir Med. 2006;100(6):972-9.

28. O'Donnell DE, Sanii R, Younes M. Improvement in exercise endurance in patients with chronic airflow limitation using continuous positive airway pressure. Am Rev Respir Dis. 1988;138(6):1510-4.

29. Panka GF, Oliveira MM, França DC, Parreira VF, Britto RR, Velloso M. Ventilatory and muscular assessment in healthy subjects during ane activity of daily living with unsupported arm elevation. Rev Bras Fisioter. 2010;14(4):337-43.

30. Moreno J, Dal Corso S, Malaguti C. Análise descritiva do uso de ventilação mecânica não invasiva durante exercício em pacientes com DPOC. ConScientiae Saúde. 2007;6(2):295-303. 